\title{
TESTING ISOSOURCE: STABLE ISOTOPE ANALYSIS OF A TROPICAL FISHERY WITH DIVERSE ORGANIC MATTER SOURCES
}

\author{
Jonathan P. Benstead, ${ }^{1,2,4}$ James G. March, ${ }^{1,5}$ Brian Fry, ${ }^{3,6}$ Katherine C. Ewel, ${ }^{3,7}$ \\ And Catherine M. Pringle ${ }^{1}$ \\ ${ }^{1}$ Institute of Ecology, University of Georgia, Athens, Georgia 30602 USA \\ ${ }^{2}$ The Ecosystems Center, Marine Biological Laboratory, Woods Hole, Massachusetts 02543 USA \\ ${ }^{3}$ USDA Forest Service, Institute of Pacific Islands Forestry, 1151 Punchbowl Street, Room 323, \\ Honolulu, Hawaii 96813 USA
}

\begin{abstract}
We sampled consumers and organic matter sources (mangrove litter, freshwater swamp-forest litter, seagrasses, seagrass epiphytes, and marine particulate organic matter [MPOM]) from four estuaries on Kosrae, Federated States of Micronesia for stable isotope $\left(\delta^{13} \mathrm{C}\right.$ and $\left.\delta^{34} \mathrm{~S}\right)$ analysis. Unique mixing solutions cannot be calculated in a dualisotope, five-endmember scenario, so we tested IsoSource, a recently developed statistical procedure that calculates ranges in source contributions (i.e., minimum and maximum possible). Relatively high minimum contributions indicate significant sources, while low maxima indicate otherwise. Litter from the two forest types was isotopically distinguishable but had low average minimum contributions $(0-8 \%$ for mangrove litter and $0 \%$ for swampforest litter among estuaries). Minimum contribution of MPOM was also low, averaging $0-13 \%$ among estuaries. Instead, local marine sources dominated contributions to consumers. Minimum contributions of seagrasses averaged $8-47 \%$ among estuaries (range $0-88 \%$ among species). Minimum contributions of seagrass epiphytes averaged 5-27\% among estuaries (range 0-69\% among species). IsoSource enabled inclusion of five organic matter sources in our dual-isotope analysis, ranking trophic importance as follows: seagrasses $>$ seagrass epiphytes $>$ MPOM $>$ mangrove forest $>$ freshwater swamp-forest. IsoSource is thus a useful step toward understanding which of multiple organic matter sources support food webs; more detailed work is necessary to identify unique solutions.
\end{abstract}

Key words: carbon; food webs; IsoSource; mangrove; Micronesia; mixing models; seagrasses; stable isotope analysis; sulfur.

\section{INTRODUCTION}

Diversity in primary producers typifies many aquatic ecosystems, resulting in multiple sources and types of organic matter entering food webs that present considerable challenges to quantitative analysis. Stomach contents of consumers can provide relatively high-resolution data on consumer diets, but are less useful for identifying the ultimate source of energy supporting a food web (i.e., its trophic base). Since the advent of affordable stable isotope analysis (SIA), ecologists have relied on this technique to trace flows of elements (particularly carbon and nitrogen) through food webs (Peterson and Fry 1987). SIA sometimes allows the unequivocal identification of important elemental

Manuscript received 6 May 2005; revised 26 July 2005; accepted 1 August 2005. S. J. Simpson.

${ }^{4}$ Present address: Department of Biological Sciences, University of Alabama, Tuscaloosa, Alabama 35487 USA. E-mail: jbenstead@bama.ua.edu

${ }^{5}$ Present address: Washington and Jefferson College, Biology Department, Washington, Pennsylvania 15301 USA.

${ }^{6}$ Present address: Coastal Ecology Institute and Department of Oceanography, Louisiana State University, Baton Rouge, Louisiana 70803 USA.

${ }^{7}$ Present address: 2126 NW 7th Lane, Gainesville, Florida 32603 USA. sources within food webs. However, SIA is also hampered by the presence of multiple potential organic matter sources. Even if all sources within a food web can be sampled and analyzed, subsequent use of mathematical mixing models for calculating contributions to species is often limited by the number of isotopes that can be included in the analysis. Data from $n$ isotope values are needed if $n+1$ organic matter sources are to be included in the mixing model. Otherwise, standard linear mixing models are unable to calculate a unique solution for source contributions (Phillips 2001).

Only a few elements can routinely be used in SIA of food webs (e.g., H, C, N, O, and S). Moreover, ecologists have often been limited by the cost of these analyses. Consequently, food web studies using data from $n$ stable isotope values (typically two) have often restricted their studies to $n+1$ organic matter sources by including only those sources either assumed to be most important or shown to be through other types of analyses. Unfortunately, inclusion only of organic matter sources assumed to be dominant may result, at best, in overestimation of their energetic significance. At worst, exclusion of some organic matter sources could lead to misinterpretation of the trophic base and structure of the food web. 


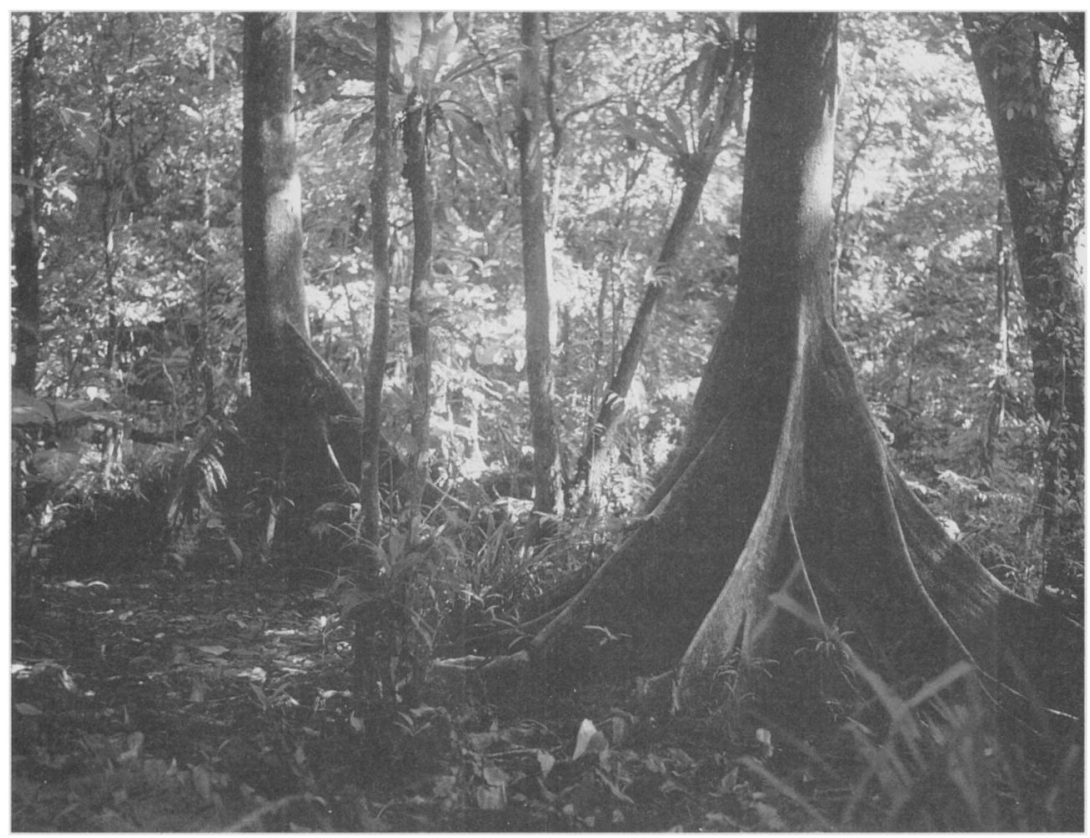

Plate 1. Undisturbed freshwater swamp-forest in the lower catchment of the Yela River, Kosrae, Federated States of Micronesia. This frequently flooded forest type, dominated by the Micronesian endemic Terminalia carolinensis (buttressed roots), is found just landward of Kosrae's thick mangrove belt. Photo credit: J. Benstead.

In response to these problems, Phillips and Gregg (2003) developed and recently introduced mixing model software (IsoSource) that is designed for situations in which $n$ isotopes are being used and more than $n+$ 1 sources are likely to be contributing to a mixture. IsoSource uses stable isotope data to calculate feasible ranges of source contributions by the following procedure. First, all possible combinations of source proportions that sum to $100 \%$ are calculated in user-specified increments (usually 1\%). Second, the predicted isotope values of each mixture are computed using linear mixing model equations that preserve mass balance (Phillips 2001). Isotope values of computed mixtures are then compared with the observed isotope values; the range of combinations that match within a userspecified tolerance value (e.g., $0.1 \%$ ) is then described.

In this study, we analyze dual stable isotope data $\left(\delta^{13} \mathrm{C}\right.$ and $\left.\delta^{34} S\right)$ from four estuaries on Kosrae; a small isolated island in the equatorial western Pacific Ocean. Estuaries on Pacific high-islands such as Kosrae receive organic matter from a diverse mixture of primary producer communities (e.g., mangrove, upland forest, phytoplankton, and seagrasses). As such, they represent classic multiple-source environments, in which identifying organic matter source contributions would typically prove problematic. IsoSource was developed for just such situations. Here, we test the usefulness and limits of the software by using IsoSource output (i.e., ranges in source contributions) to examine the relative significance of five organic matter sources for 35 fish and crustacean species that are important, either commercially or for subsistence, on Kosrae.

\section{Materials AND Methods}

Study area

Kosrae is located in the eastern Caroline Islands $\left(5^{\circ} 16^{\prime}-5^{\circ} 22^{\prime} \mathrm{N}, 162^{\circ} 54^{\prime}-163^{\circ} 02^{\prime} \mathrm{E}\right)$. It is the easternmost island state $\left(5^{\circ} 18^{\prime} \mathrm{N}, 168^{\circ} 58^{\prime} \mathrm{E}\right)$ in the Federated States of Micronesia. Kosrae is a small $\left(112 \mathrm{~km}^{2}\right)$ volcanic high-island (maximum elevation $629 \mathrm{~m}$ ). Annual mean temperature is $27^{\circ} \mathrm{C}$, and average annual rainfall ranges from $5000 \mathrm{~mm}$ at the coast to $7500 \mathrm{~mm}$ in the interior (Whitesell et al. 1986). Marked seasonality in rainfall is not evident on Kosrae (Merlin et al. 1993). The island has $97 \%$ forest cover composed of undisturbed forest, agroforest, and secondary forest (Whitesell et al. 1986). Wetlands occupy $29 \%$ of the island, of which mangrove forest makes up $14 \%$ (1562 ha) in a belt of vegetation up to $750 \mathrm{~m}$ thick occupying twothirds of the shoreline (Whitesell et al. 1986). Tropical freshwater swamp-forest dominated by the Micronesian endemic Terminalia carolinensis covers $5 \%$ of the island's area; agroforests that are functional wetlands occupy another $10 \%$. The island is surrounded by a continuous fringing reef of variable width $(50-500 \mathrm{~m})$. Tides are mixed semidiurnal with a mean tidal amplitude of $\sim 1 \mathrm{~m}$.

\section{Sample collection and analysis}

All samples were collected during September-December 2000 from the lower catchments and estuaries of four small rivers (Finkol, Okat, Yela, and Yeseng). In each freshwater swamp-forest habitat (see Plate 1) we sampled fresh leaves from replicate trees $(n=3)$ 
of three dominant tree species: Terminalia carolinensis, Barringtonia racemosa, and Horsfieldia nunu. We also collected three grab samples of mixed-species leaf litter from stream channels. In mangrove forest, leaves were collected from all major mangrove tree species (5-6 species at each site). Where possible, leaves were gathered from three different individuals in each of three hydrogeomorphic zones: riverine, fringe, and interior. We picked several undamaged distal leaves on low branches (shade leaves). Hereafter, we refer to leaf material as leaf litter. Replicates $(n=3)$ of the two dominant seagrass species (Enhalus acoroides and Thalassia hemprichii) were collected from different individuals on reef flat areas at each of the sites, where possible. Seagrasses were transported to the laboratory, where epiphytes (e.g., attached algae, microorganisms) were removed using a soft toothbrush. Epiphyte slurries were frozen immediately and transported to the University of Georgia. Other organic matter sources were dried for $72 \mathrm{~h}$ at $60^{\circ} \mathrm{C}$. Dried seagrasses and tree leaves were subsequently ground to a fine powder in a ball mill. Seagrass epiphyte slurries were thawed, filtered onto GF filters, and dried for $72 \mathrm{~h}$ at $55^{\circ} \mathrm{C}$. Dried epiphyte material was removed from the filter, transferred to a vial, and ground with a glass rod.

We lacked appropriate sampling gear for collection of marine particulate organic matter (MPOM) that was uncontaminated by terrestrial or coastal detritus. For this reason, we used published values for MPOM $\delta^{13} \mathrm{C}$ and $\delta^{34} \mathrm{~S}$ of $-22 \pm 1 \%$ and $19.5 \pm 1 \%$, respectively, in mixing model calculations. $\delta^{13} \mathrm{C}$ of marine phytoplankton shows low variability around the $-22 \%$ value near the equator (Goericke and Fry 1994). The $\delta^{34} S$ value we used represents the $+21 \%$ of seawater sulfate minus $1.5 \%$ average fractionation during algal S synthesis (Trust and Fry 1992).

Fishes from mangrove and reef flat areas were collected using a monofilament gill net $(30 \times 1.5 \mathrm{~m} ; 20$ $\mathrm{mm}$ mesh size) or by angling. Mangrove crabs (Scylla serrata) were caught in mangrove habitat either in the gill net or in baited traps. All taxa were sampled within $500 \mathrm{~m}$ of the mouths of the four estuaries. Where possible, we collected three replicates of each species from each habitat at each focal site (Appendix A). A total of 35 species of fish and crustacean species were collected for isotope analysis (Appendix A). Between eight and 18 fish species were sampled from each estuary. Small fishes ( $<100 \mathrm{~mm}$ total length) and small crabs ( $<80 \mathrm{~mm}$ carapace width) were frozen whole. Large fishes were subsampled by removing and freezing lateral muscle from the caudal peduncle. A single chela was removed from large crabs. All consumer samples were transported frozen to the University of Georgia, USA. Consumer samples were subsequently thawed and muscle tissue removed using a clean scalpel. Muscle samples were dried for $96 \mathrm{~h}$ at $55^{\circ} \mathrm{C}$ and ground by hand using a pestle and mortar.
Ground samples for $\delta^{13} \mathrm{C}$ and $\delta^{15} \mathrm{~N}$ analysis were run at the Institute of Ecology's Analytical Chemistry Laboratory in a Carlo Erba NA 1500 CHN analyzer (Carlo Erba Instrumentazione, Milan, Italy) coupled to a Finnigan Delta $\mathrm{C}$ isotope ratio mass spectrometer (Thermo Electron, Waltham, Massachusetts, USA) operating as a continuous flow system. Reproducibility was monitored using a bovine liver standard. Precision was better than $\pm 0.2 \%$ o ( $1 \mathrm{SD}$ ). Samples for $\delta^{34} \mathrm{~S}$ analysis were run at the Environmental Isotope Laboratory at the University of Waterloo (Canada) on a Micromass IsoChrom continuous flow stable isotope mass spectrometer (GV Instruments, Manchester, UK) coupled to a Carlo Erba elemental analyzer. Reproducibility was monitored using several organic reference standards. Range in measurement error was estimated at $\pm 0.7-$ $1.0 \%$. Isotope values are expressed as $\delta^{13} \mathrm{C}, \delta^{15} \mathrm{~N}$, or $\delta^{34} \mathrm{~S}$ (with units of $\%$ ) according to the following equation:

$$
\delta^{13} \mathrm{C}, \delta^{15} \mathrm{~N} \text {, or } \delta^{34} \mathrm{~S}=\left[\left(R_{\text {sample }} / R_{\text {standard }}\right)-1\right] \times 1000
$$

where $R={ }^{13} \mathrm{C} /{ }^{12} \mathrm{C},{ }^{15} \mathrm{~N} /{ }^{14} \mathrm{~N}$ or ${ }^{34} \mathrm{~S} /{ }^{32} \mathrm{~S}$. Reference standards were PeeDee Belemnite Carbonate, atmospheric $\mathrm{N}_{2}$, and Canyon Diablo Troilite for $\delta^{13} \mathrm{C}, \delta^{15} \mathrm{~N}$, and $\delta^{34} \mathrm{~S}$, respectively.

\section{IsoSource analysis}

All five organic matter sources were entered into IsoSource calculations: mangrove leaf litter, freshwater swamp-forest leaf litter, seagrasses, seagrass epiphytes, and marine particulate organic matter (estuary-specific means and standard errors for each category). For mangrove litter, we included dominant tree species at each site only, combining values from each hydrogeomorphic sub-habitat. Source increment was set at $1 \%$. Tolerance was initially set at $0.1 \%$; if mixture isotope values were out of bounds (i.e., outside the polygon delineated by the five food web end members; Phillips 2001), we incrementally increased the tolerance value by $0.1 \%$ up to a maximum of $0.5 \%$. Only $\delta^{13} \mathrm{C}$ and $\delta^{34} \mathrm{~S}$ were entered into IsoSource calculations because we wanted to restrict our analysis to two elements (the most common situation). Moreover, relative uniformity in the mean $\delta^{15} \mathrm{~N}$ values of the five organic matter sources at each site limited the utility of these data (Appendix B). Trophic fractionation of $\mathrm{C}$ and $\mathrm{S}$ isotopes is relatively small (compared to that of $\mathrm{N}$ isotopes; McCutchan et al. 2003). In addition, we lacked information about the number of trophic levels between basal resources and consumers. Consequently, we did not correct consumer $\delta^{13} \mathrm{C}$ and $\delta^{34} \mathrm{~S}$ values for trophic fractionation.

We restrict our use of IsoSource output to ranges in source contributions (i.e., minimum to maximum feasible; Phillips and Gregg 2003, see Discussion) for each source and consumer species. However, we report ranges as 1st percentile to 99th percentile of source contribution distributions in order to truncate distributions 

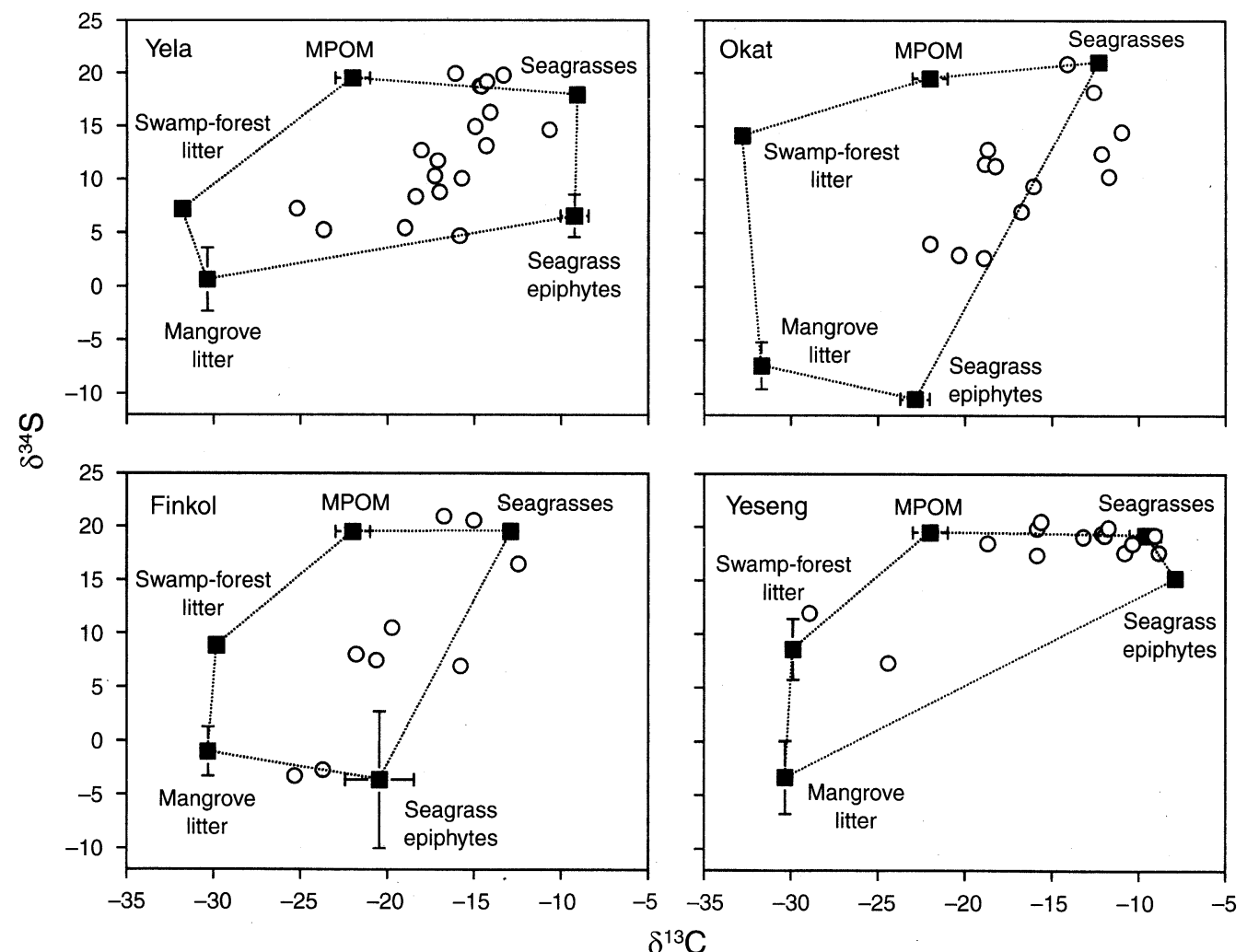

FIG. 1. Stable isotope ratios $\left(\delta^{34} \mathrm{~S}\right.$ vs. $\left.\delta^{13} \mathrm{C}\right)$ of organic matter sources (solid squares, mean \pm SE) and fishes plus Scylla serrata (open circles, mean) from the four estuaries of Kosrae, Federated States of Micronesia, September-December 2000. Marine particulate organic matter (MPOM) values are based on published data.

that have very small numbers of observations in long tails. Interpretation of these minima and maxima deserves some discussion here. Low maxima are least ambiguous and therefore most useful; they indicate that the organic matter source can be rejected as important. Relatively high minima indicate that the source may be important, if all likely sources have been included in the analyses. Neither high maxima nor low minima are particularly useful. Large ranges between minima and maxima are clearly not informative, unless the minimum is relatively high. Small ranges represent relatively well constrained estimates of the source contribution, again assuming that all likely food sources have been sampled.

\section{RESUlts}

Carbon and sulfur isotopes provided good discrimination among organic matter sources, with mean $\delta$ values for all sources separated by at least $5 \%$ on one or more biplot axes at each site (Fig. 1). Patterns in $\delta^{13} \mathrm{C}$ were consistent among estuaries for all organic matter sources except seagrass epiphytes and fell within the range expected based on other studies (Fig. 1 and Appendix B; Boon and Bunn 1994). Patterns in mean $\delta^{34} \mathrm{~S}$ were more variable among estuaries for mangrove litter (range, $-7.3 \%$ o to $0.6 \%$ ), swamp-forest litter (range, $7.2 \%$ to $14.1 \%$ ), and seagrasses (range,
$17.9 \%$ to $21.0 \%$ ); however, they fell within the range expected for plants relying on sulfide, rainwater sulfate, and seawater sulfate, respectively (Fry et al. 1982). Values for seagrass epiphytes were highly variable among estuaries for both $\delta^{13} \mathrm{C}$ (range, $-22.9 \%$ to $-7.9 \%$ ) and $\delta^{34} \mathrm{~S}$ (range, $-10.5 \%$ to $15.2 \%$; Fig. 1 and Appendix B). Most consumers fell within the polygons delineated by the five source end members at each site (Fig. 1), suggesting that we sampled all major organic matter sources at each estuary.

IsoSource estimates of feasible contribution of mangrove litter to consumers averaged 3.6\% (minima) and 20.5\% (maxima) among species (Fig. 2, Appendix C). Ranges among species were $0-32 \%$ (minima) and $0-$ $67 \%$ (maxima). Estimates of feasible contributions of freshwater swamp-forest litter averaged $0 \%$ (minima) and $17 \%$ (maxima) among all species (Fig. 2). Corresponding ranges were $0-0 \%$ (minima) and $0-68 \%$ (maxima). Feasible contributions of marine particulate organic matter to consumer growth averaged 6.3\% (minima, range $0-59 \%$ ) and $27 \%$ (maxima, range 077\%; Fig. 2).

Average minima for feasible contributions of seagrasses among all species was $29 \%$ (maxima $53.6 \%$; Fig. 2). Ranges among species were $0-88 \%$ (minima) and $0-97 \%$ (maxima). Estimates of feasible seagrass epiphyte contributions averaged 15\% (minima, range 

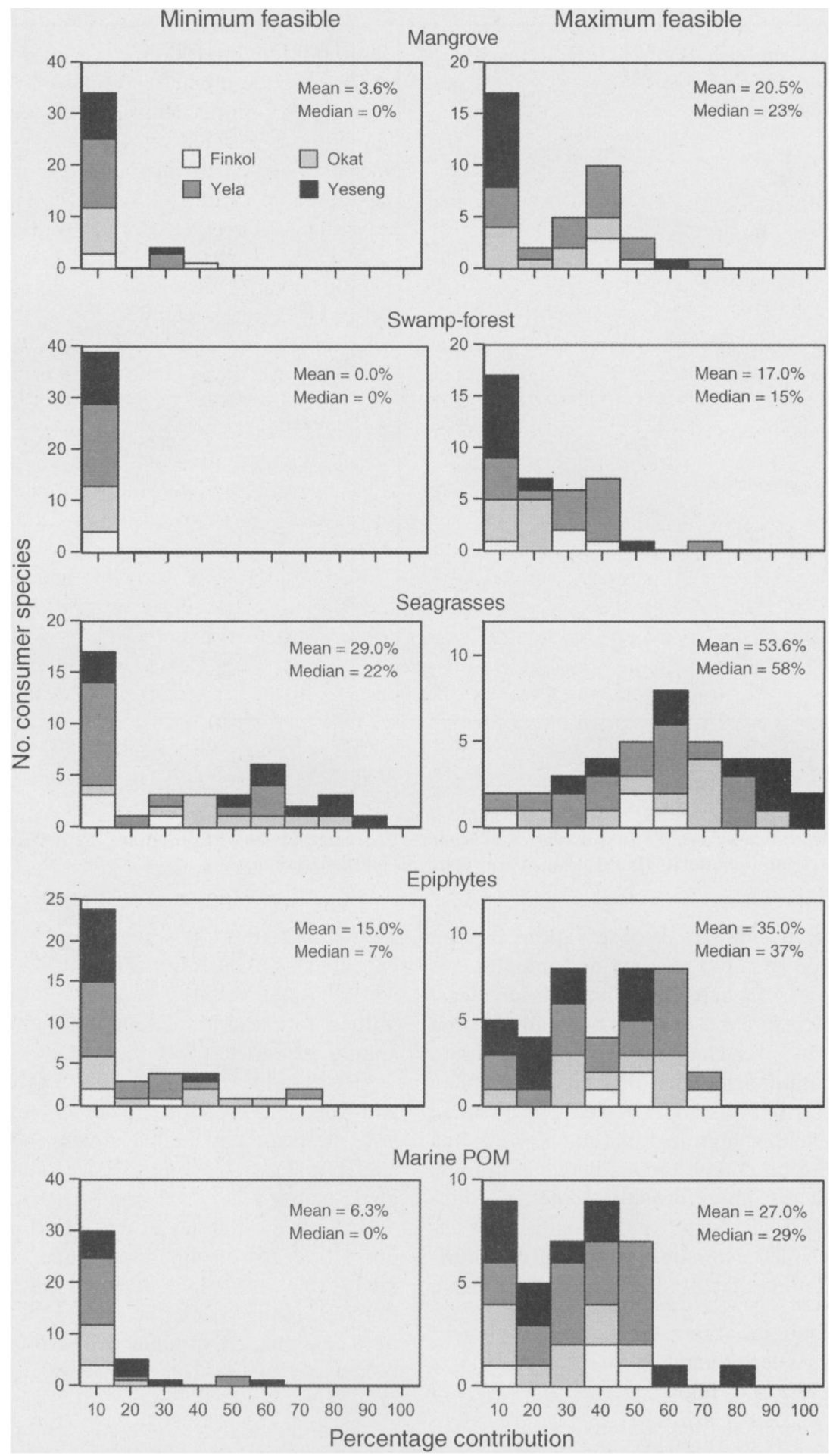

Fig. 2. Histograms of minimum and maximum feasible contributions of five organic matter sources to consumer species in the four estuaries, Kosrae, Federated States of Micronesia, September-December 2000. 
0-69\%) and 35\% (maxima, range 0-69\%; see Fig. 2). Combined, seagrasses and seagrass epiphytes dominated estimated contributions to the growth of fish and Scylla serrata in each estuary (Fig. 2).

\section{DISCUSSION}

A recent series of papers has greatly strengthened the statistical underpinnings of stable isotope interpretations, providing much needed philosophical and practical guidance in the interpretation of mixing models (Phillips 2001, Phillips and Gregg 2001, Phillips and Koch 2002). The most recent paper in this series introduces software that calculates multitudinous feasible solutions to mixing problems in which there are multiple sources and no unique solution can be inferred (Phillips and Gregg 2003).

IsoSource output showed that contributions from mangrove-derived organic matter were variable and relatively low among estuaries and species, consistent with other studies that have used multiple stable isotope analysis to examine trophic importance of mangrovederived organic matter in estuarine food webs (e.g., Rodelli et al. 1984, Hemminga et al. 1994, Marguillier et al. 1997). Isotope research to date suggests that the influence of mangrove-derived organic material is typically limited to areas close to mangrove forest. This is due either to rapid dilution of mangrove organic material by other sources with distance, or to decreasing food quality as mangrove litter becomes increasingly refractory as it moves farther from its original source, or a combination of these factors. All the consumers in this study were collected within $500 \mathrm{~m}$ of the mangrove fringe. The low contributions of mangrove litter that we found are probably due to the relatively higher quality (and production) of organic matter from seagrass communities.

Contribution of litter from freshwater swamp-forest was also relatively low. Discrimination of mangrove litter from other $\mathrm{C}_{3}$ plants has rarely been attempted in isotope studies, because these two sources are usually impossible to distinguish using $\delta^{13} \mathrm{C}$, the most commonly used isotope value. Our use of $\delta^{34} \mathrm{~S}$ allowed us to partition these two sources. In this study, the 1 st percentile of source contribution estimates for all species and sites was zero, indicating that swamp-forest litter may contribute no organic matter to Kosrae's inshore food webs. Litter production in Terminalia-dominated swamp-forest is as high as that in mangrove on Kosrae (1181 vs. $1044 \mathrm{~g}$ ash-free dry mass $\cdot \mathrm{m}^{-2} \cdot \mathrm{yr}^{-1}$; Chimner and Ewel 2004; R. Hauff, unpublished data). Swamp-forest is also frequently flooded, promoting overland flow toward stream channels and the coastal margin (Drexler and Ewel 2001). Moreover, decomposition of senescent Terminalia carolinensis leaves is slow in the lower Yela River $(<1 \% / d ;$ J. G. March and J. P. Benstead, unpublished data). It therefore seems probable that storms flush much of the swamp-forest litter production into estuaries and adjacent coastal ar- eas. However, IsoSource results demonstrated that its incorporation into food webs is very limited, due either to low relative inputs or food quality.

IsoSource output showed that seagrasses and their epiphytes dominated source contributions to consumer species sampled in this study. Many continent-based studies have estimated similarly high levels of seagrass-derived organic matter contributions to inshore food webs (Loneragan et al. 1997, Marguillier et al. 1997). Fewer studies have studied the relative contributions of seagrass epiphytes to consumers using stable isotopes but most have shown relatively large contributions from these inconspicuous primary producers (e.g., Moncreiff and Sullivan 2001). For example, invertebrates in Gulf of Mexico seagrass meadows fed largely on algae growing on seagrass blades, and their $\delta^{13} \mathrm{C}$ tracked epiphyte values more closely than those of seagrass in inter-site comparisons (Kitting et al. 1984).

IsoSource results showed that contributions from marine particulate organic matter (e.g., oceanic phytoplankton) to consumers were relatively small. This is not surprising. Concentrations of chlorophyll $a$ are low in Kosrae's estuaries and coastal waters (S. Nixon, unpublished data), which lack the shallow, productive shelf environment common to many continental regions. Rates of pelagic primary production are low in the tropical Pacific (20-50 g C. $\mathrm{m}^{-2} \cdot \mathrm{yr}^{-1}$; Dalzell et al. 1996). In contrast, primary production by seagrasses can exceed $800 \mathrm{~g} \mathrm{C} \cdot \mathrm{m}^{-2} \cdot \mathrm{yr}^{-1}$ (Duarte and Chiscano 1999). Despite high potential connectivity, subsidies of phytoplankton-based organic matter into inshore food webs from relatively unproductive surrounding ocean may therefore be low on small oceanic islands, especially compared to local organic matter production by seagrass communities.

IsoSource enabled the inclusion of five potentially important organic matter sources in our dual-isotope analysis. Subsequent pooling of species minima and maxima in histograms allowed us to draw broad conclusions about the relative importance of organic matter sources for estuarine food webs on the island. For example, we can rank the organic matter sources in trophic importance with some confidence: seagrasses $>$ seagrass epiphytes $>$ marine particulate organic matter $>$ mangrove forest $>$ freshwater swamp-forest. The output also pointed to differences in trophic support among the four estuaries we studied. However, the value of the output was lower at the species level. The trophic support of some species could not be identified with confidence, either because of large ranges in source contribution or because they fell out-of-bounds in the IsoSource analysis (i.e., their isotope values were outside the mixing polygon). In many cases (see Fig. 1), corrections for trophic fractionation would have brought these values within bounds (i.e., inside the mixing polygon) and allowed IsoSource estimates to be made using our specified range of tolerance values. 
We restricted our reporting of IsoSource output to feasible ranges in source contributions. Phillips and Gregg (2003) stress that this is the correct way to view and report the model output. IsoSource also outputs the mean for these distributions, among other descriptors such as standard deviation and various percentiles. All the solutions identified by the model are consistent with isotopic mass balance; there is no a priori reason to prefer one solution over another on a strictly isotopic basis. But in a real food web with various food sources, factors such as availability, palatability, and productivity will vary strongly among organic matter sources, and these inequalities will determine the unique solution of what gets eaten and assimilated. IsoSource does not share the bias of real food webs and so there is no reason to expect that its distribution means will accurately index the unique solutions that scientists seek. Consequently, mean values describing the average of all the source contribution estimates should be treated with utmost caution and never equated with unique solutions to the mixing problem.

IsoSource yields one firm result: minimum and maximum values for each source contribution. These values are constrained by mass balance. Reporting minimummaximum constraints is a safe and often enlightening use of IsoSource output and, importantly, emphasizes that unique solutions have yet to be found. Information from multiple species (e.g., in histograms) may allow relatively firm conclusions about the relative importance of sources for the trophic support of a food web. Another route is to use additional information to further sort the results, as pointed out by Phillips and Gregg (2003). Sometimes even very qualitative information will rapidly narrow the possible range of feasible solutions toward the unique solution. Procedures for postprocessing IsoSource output to consider other non-isotopic constraints (e.g., sorting, in which source A must have a greater contribution than source $B$ ) have been provided at the IsoSource web site. ${ }^{8}$ Sorting can be a powerful and rapid way to narrow the range of feasible solutions toward the unique solution. An example would be in a food web study where stomach content analyses reliably show that contributions from fish are greater than contributions from invertebrates, so that ranking of potential source contributions becomes possible. However, ranking must be accurate and this is often a difficult challenge. After all, it is because these contributions are genuinely hard to estimate that ecologists originally turned to isotope tracers.

An important point about natural-abundance isotope surveys is that they are most powerful in disproving the importance of certain sources, but are usually very weak in the converse sense: showing that a source of interest is highly important. Crossing the line from disproof to nailing down a unique solution probably re-

\footnotetext{
${ }^{8}\langle$ http://www.epa.gov/wed/pages/models/isosource/
} isosource.htm $\rangle$ quires experimentation in most cases, an additional step beyond the survey of natural systems. In some cases, sampling along transects where one source is increasingly important, or following seasonal or spatial shifts in natural isotope distributions, can provide fairly unambiguous natural experiments (Finlay et al. 2002, McCutchan and Lewis 2002). But many times, adding enriched tracer to shift isotope values artificially will be required to establish the importance of a source (Wollheim et al. 1999). Fortunately, many ecologists are beginning to combine surveys of the natural isotope distributions with isotope shift experiments, striving to use both approaches to advantage by disproving the importance of certain sources in surveys while positively quantifying the importance of other sources in isotope addition experiments. This kind of additional information can be used also to help sort the output from the new and elegant IsoSource software, to find unique solutions for these difficult multiple source problems.

The IsoSource approach is an extremely useful addition to the rapidly growing roster of statistical techniques available to those analyzing isotope data. It can often provide narrow ranges of source contribution estimates and is particularly useful for showing that a source is not important for a food web. Used carefully, it represents a step toward understanding which organic matter sources support food webs; more detailed work is necessary to identify the unique solution within ranges of feasible solutions.

\section{ACKNOWLEDGMENTS}

This research was funded through a research joint venture agreement between the USDA and CMP at the University of Georgia. We are grateful to Moses Palik, Jason Jack, Rob Hauff, Sarah March, and Maxwell Salik for assistance in the field. Erick Waguk, Simpson Abraham, and the staff of Kosrae's Development Review Commission helped with logistics. Lynne Parenti identified Oxyeleotris sp. We thank Tom Maddox, Bill Mark, and Bob Drimmie for stable isotope analyses. Don Phillips and an anonymous reviewer provided insightful comments on an earlier version of the manuscript.

\section{Literature Cited}

Boon, P. I., and S. E. Bunn. 1994. Variations in the stable carbon isotope composition of aquatic plants and their implications for food web analysis. Aquatic Botany 48:99108.

Chimner, R. A., and K. C. Ewel. 2004. Differences in carbon fluxes between forested and cultivated Micronesian tropical peatlands. Wetlands Ecology and Management 12:419427.

Dalzell, P., T. J. H. Adams, and N. V. C. Polunin. 1996. Coastal fisheries in the Pacific islands. Oceanography and Marine Biology: an Annual Review 34:395-531.

Drexler, J. Z., and K. C. Ewel. 2001. Effect of the 19971998 ENSO-related drought on hydrology and salinity in a Micronesian wetland complex. Estuaries 24:347-356.

Duarte, C. M., and C. L. Chiscano. 1999. Seagrass biomass and production: a reassessment. Aquatic Botany 65:159174.

$\rightarrow$ Finlay, J. C., S. Khandwala, and M. E. Power. 2002. Spatial scales of carbon flow in a river food web. Ecology 83: 1845-1859. 
Fry, B., R. S. Scalan, J. K. Winters, and P. L. Parker. 1982. Sulphur uptake by salt grasses, mangroves, and seagrasses in anaerobic sediments. Geochimica et Cosmochimica Act $\rightarrow$ 46:1121-1124.

Goericke, R., and B. Fry. 1994. Variations of marine plankton $\delta^{13} \mathrm{C}$ with latitude, temperature, and dissolved $\mathrm{CO}_{2}$ in the world ocean. Global Biogeochemical Cycles 8:85-90.

Hemminga, M. A., F. J. Slim, J. Kazungu, G. M. Ganssen, J. Nieuwenhuize, and N. M. Kruyt. 1994. Carbon outwelling from a mangrove forest with adjacent seagrass beds and coral reefs (Gazi Bay, Kenya). Marine Ecology Progress Series 106:291-301.

Kitting, C. L., B. Fry, and M. D. Morgan. 1984. Detection of inconspicuous epiphytic algae supporting food webs in seagrass meadows. Oecologia 62:145-149.

Loneragan, N. R., S. E. Bunn, and D. M. Kellaway. 1997. Are mangroves and seagrasses sources of organic carbon for penaeid prawns in a tropical Australian estuary? A multiple stable-isotope study. Marine Biology 130:289-300.

Marguillier, S., G. van der Velde, F. Dehairs, M. A. Hemminga, and S. Rajagopal. 1997. Trophic relationships in an interlinked mangrove-seagrass ecosystem as traced by $\delta^{13} \mathrm{C}$ and $\delta^{15} \mathrm{~N}$. Marine Ecology Progress Series 151:115121.

$\rightarrow$ McCutchan, J. H., Jr., and W. M. Lewis, Jr. 2002. Relative importance of carbon sources for macroinvertebrates in a Rocky Mountain stream. Limnology and Oceanography 47: $742-752$.

McCutchan, J. H., Jr., W. M. Lewis, Jr., C. Kendall, and C. C. McGrath. 2003. Variation in trophic shift for stable isotope ratios of carbon, nitrogen, and sulfur. Oikos 102: 378-390.

Merlin, M., R. Taulung, and J. Juvik. 1993. Sahk Kap Ac Kain In Acn Kosrae (Plants and environments of Kosrae). East-West Center, Honolulu, Hawaii, USA.

Moncreiff, C. A., and M. J. Sullivan. 2001. Trophic importance of epiphytic algae in subtropical seagrass beds: ev- idence from multiple stable isotope analyses. Marine Ecology Progress Series 215:93-106.

Peterson, B. J., and B. Fry. 1987. Stable isotopes in ecosystem studies. Annual Review of Ecology and Systematics 18:293-320.

Phillips, D. L. 2001. Mixing models in analyses of diet using multiple stable isotopes: a critique. Oecologia 127:166170.

Phillips, D. L., and J. W. Gregg. 2001. Uncertainty in source partitioning using stable isotopes. Oecologia 127:171179.[See also Erratum, Oecologia 128:304.]

Phillips, D. L., and J. W. Gregg. 2003. Source partitioning using stable isotopes: coping with too many sources. Oecologia 136:261-269.

Phillips, D. L., and P. L. Koch. 2002. Incorporating concentration dependence in stable isotope mixing models. Oecologia 130:114-125.

Rodelli, M. R., J. N. Gearing, P. J. Gearing, N. Marshall, and A. Sasekumar. 1984. Stable isotope ratio as a tracer of mangrove carbon in Malaysian ecosystems. Oecologia 61: 326-333.

Trust, B. A., and B. Fry. 1992. Stable sulphur isotopes in plants: a review. Plant, Cell and Environment 15:11051110 .

Whitesell, C. D., C. D. MacLean, M. C. Falanruw, T. G. Cole, and A. H. Ambacher. 1986. Vegetation survey of Kosrae, Federated States of Micronesia. U.S. Forest Service Resource Bulletin PSW-17. USDA Pacific Southwest Forest and Range Experiment Station, Berkeley, California, USA

Wollheim, W. M., B. J. Peterson, L. A. Deegan, M. Bahr, J. E. Hobbie, D. Jones, W. B. Bowden, A. E. Hershey, G. W. Kling, and M. C. Miller. 1999. A coupled field and modeling approach for the analysis of nitrogen cycling in streams. Journal of the North American Benthological Society 18:199-221.

\section{APPENDIX A}

Fish and crustacean species sampled in this study with common names in English and Kosraean, trophic guild, and number of replicates analyzed for stable isotope ratios from the four estuaries sampled (Ecological Archives E087-018-A1).

\section{APPENDIX B}

Mean $\delta^{13} \mathrm{C}, \delta^{15} \mathrm{~N}$, and $\delta^{34} \mathrm{~S}$ values $( \pm$ SE where $n>1)$ for organic matter sources and consumer species sampled from the catchments and estuaries of the Finkol, Okat, Yela, and Yeseng rivers, Kosrae, Federated States of Micronesia, SeptemberDecember, 2000 (Ecological Archives E087-018-A2).

\section{APPENDIX C}

Ranges of feasible percentage contributions (1st-9.9th percentile) of five dominant organic matter sources to carbon and sulfur assimilated by fishes and Scylla serrata from the four estuaries on Kosrae, Federated States of Micronesia, SeptemberDecember, 2000, based on ${ }^{13} \mathrm{C}$ and $\delta^{34} \mathrm{~S}$ and IsoSource source partitioning software (Ecological Archives E087-018-A3). 